\title{
Efficiency enhancement of a-Si and CZTS solar cells using different thermoelectric hybridization strategies
}

\author{
Gaetano Contento $^{\mathrm{a}}$, Bruno Lorenzi ${ }^{\mathrm{b}, *}$, Antonella Rizzo ${ }^{\mathrm{a}}$, Dario Narducci ${ }^{\mathrm{b}}$ \\ ${ }^{a}$ ENEA - Italian National Agency for New Technologies, Energy and Sustainable Economic \\ Development, Brindisi Research Centre, SS 7 Appia km 706, I-72100 Brindisi, Italy \\ ${ }^{b}$ Dept. of Materials Science, University of Milano Bicocca, via R. Cozzi 55, I-20125 Milan, \\ Italy
}

\begin{abstract}
The performances of two hybrid thermoelectric photovoltaic systems are compared. In the first instance, a photovoltaic (PV) device and a thermoelectric generator (TEG) are optically coupled using a vacuum-sealed compound parabolic concentrator (CPC). As an alternative, PV and TEG devices are thermally coupled putting them directly in contact to each other. Single-junction a-Si and heterojunction $\mathrm{Cu}_{2} \mathrm{ZnSnS}_{4}$ (CZTS) have been considered as PV systems. The two systems are studied by varying the heat transfer coefficient of the cooling system between the TEG cold side and the ambient, the TEG device fill factor, and the optical concentration. Hybridization, in both configurations, always enhances the efficiencies, up to $\approx 57 \%$ for single-junction a-Si and up to $\approx 35 \%$ for the heterojunction CZTS. It will be shown that while direct thermal contact enables larger efficiencies, optical coupling grants lower temperatures at the PV side, enhancing reliability and lifetime. Further advantages and limitations of both configurations will be discussed.
\end{abstract}

Keywords: Photovoltaics, Thermoelectricity, Solar energy

${ }^{*}$ Corresponding author

Preprint submitted to Energy

April 4, 2017 


\begin{tabular}{|c|c|c|c|}
\hline \multicolumn{4}{|c|}{ Nomenclature } \\
\hline$\alpha_{\mathrm{bc}}$ & $\begin{array}{l}\text { Back-contact absorption co- } \\
\text { efficient }\end{array}$ & $P_{\mathrm{SSA}}^{\mathrm{in}, \mathrm{OC}}$ & $\begin{array}{l}\text { Heat directly absorbed by } \\
\text { TEG hot-side in the OC }\end{array}$ \\
\hline$\alpha_{\mathrm{ssa}}$ & Solar Selective Absorption & \multirow{2}{*}{$P_{\mathrm{teg}}^{\mathrm{in}, \mathrm{TC}}$} & \multirow[b]{2}{*}{$\begin{array}{l}\text { Total power without ther- } \\
\text { mal losses absorbed by TEG } \\
\text { in TC case, } W\end{array}$} \\
\hline $\bar{T}$ & $\begin{array}{l}\text { (SSA) coefficient } \\
\text { Average temperature be- } \\
\text { tween } T_{\mathrm{H}} \text { and } T_{\mathrm{C}}, K\end{array}$ & & \\
\hline$\eta_{\text {htepv }}$ & $\begin{array}{l}\text { Efficiency of the HTEPV } \\
\text { systems }\end{array}$ & \multirow[t]{2}{*}{$P_{\text {teg }}^{\text {in,OC }}$} & \multirow{2}{*}{$\begin{array}{l}\text { Total power without ther- } \\
\text { mal losses absorbed by TEG } \\
\text { in OC case, } W\end{array}$} \\
\hline \multirow{3}{*}{$\begin{array}{l}\eta_{\mathrm{ot}} \\
\eta_{\mathrm{pv}} \\
\eta_{\mathrm{pv}}^{0}\end{array}$} & Opto-thermal efficiency & & \\
\hline & Efficiency of the sole PV cell & \multirow[t]{2}{*}{$P_{\text {teg }}^{\text {in }}$} & \multirow{2}{*}{$\begin{array}{l}\text { Power absorbed by the hot- } \\
\text { side of the TEG despite of } \\
\text { thermal losses, } W\end{array}$} \\
\hline & $\begin{array}{l}\text { Efficiency of the PV cell at } \\
\text { standard temperature }\end{array}$ & & \\
\hline$\eta_{\text {teg }}$ & $\begin{array}{l}\text { Efficiency of the thermoelec- } \\
\text { tric device }\end{array}$ & $Q_{\text {teg }}$ & $\begin{array}{l}\text { Heat flowing within th } \\
\text { TEG, } W\end{array}$ \\
\hline$\gamma$ & $\begin{array}{l}\text { Temperature coefficient of } \\
\text { the PV cell, } K^{-1}\end{array}$ & \multirow[t]{2}{*}{$R_{\text {down }}$} & \multirow{2}{*}{$\begin{array}{l}\text { Thermal resistance encoun- } \\
\text { tered by the heat flowing re- } \\
\text { spectively toward the bot- } \\
\text { tom of the device, } \frac{W}{K}\end{array}$} \\
\hline$\rho_{\mathrm{cpc}}$ & $\begin{array}{l}\text { Optical concentrator trans- } \\
\text { mittance }\end{array}$ & & \\
\hline$\tau_{\text {enc }}$ & $\begin{array}{l}\text { Encapsulation } \\
\text { tance }\end{array}$ & \multirow[t]{2}{*}{$R_{\text {up }}$} & \multirow{2}{*}{$\begin{array}{l}\text { Thermal resistance encoun- } \\
\text { tered by the heat flowing re- } \\
\text { spectively toward the top o } \\
\text { the device, } \frac{W}{K}\end{array}$} \\
\hline \multirow{5}{*}{$\begin{array}{l}A_{\text {teg }} \\
A_{n} \\
A_{p} \\
C_{\text {opt }} \\
f\end{array}$} & TEG area, $m^{2}$ & & \\
\hline & Thermolectric n-leg area, $m^{2}$ & $S$ & \multirow{4}{*}{$\begin{array}{l}\text { PV area, } m^{2} \\
\text { Ambient temperature, } K \\
\text { TEG cold-side temperature } \\
K\end{array}$} \\
\hline & Thermolectric p-leg area, $m^{2}$ & $T_{\mathrm{a}}$ & \\
\hline & Optical concentration & $T_{\mathrm{C}}$ & \\
\hline & Fraction of $P_{\mathrm{pv}}^{\mathrm{in}, \mathrm{OC}}$ which & & \\
\hline$F F$ & $\begin{array}{l}\text { flows towards the TEG de- } \\
\text { vice instead than towards } \\
\text { the device front surface }\end{array}$ & $T_{\text {enc }}$ & $\begin{array}{l}\text { Temperature of the encapsu- } \\
\text { lation, } K\end{array}$ \\
\hline \multicolumn{2}{|c|}{$\begin{array}{l}F F_{\text {htepv }} \text { HTEPV fill factor with re- } \\
\text { spect to the PV area } S\end{array}$} & $T_{\mathrm{H}}$ & $\begin{array}{l}\text { TEG hot-side temperature, } \\
K\end{array}$ \\
\hline \multirow{5}{*}{$\begin{array}{l}F F_{\text {teg }} \\
G \\
L_{2 \mathrm{a}} \\
P_{\mathrm{pv}}^{\text {in,OC }}\end{array}$} & TEG device fill factor & $T_{\mathrm{pv}}$ & Solar cell working tempera- \\
\hline & Solar irradiance, $\frac{W}{m^{2}}$ & \multirow{2}{*}{$T_{\mathrm{sc}}$} & \multirow[b]{2}{*}{$\begin{array}{l}\text { Solar cell standard tempera- } \\
\text { ture, } K\end{array}$} \\
\hline & $\begin{array}{l}\text { Sub-gap fraction of the solar } \\
\text { spectrum }\end{array}$ & & \\
\hline & Heat generated in PV mod- & $Z$ & TEG figure of merit, $K^{-1}$ \\
\hline & $\begin{array}{l}\text { ule by carrier thermalization } \\
\text { in the OC case, } W\end{array}$ & $h$ & $\begin{array}{l}\text { Convective heat loss coeffi- } \\
\text { cient, } W / m^{2} K\end{array}$ \\
\hline
\end{tabular}




\section{Introduction}

A sustainable energy future is a key challenge for the XXI Century. A large reduction in greenhouse gas emissions is needed and urgent to limit global warming and its consequence on human health $[1,2]$. Solar energy is nowadays the leading renewable source and photovoltaics is a well-assessed key renewable technology. However, trade-off between cost and conversion efficiency sets its competitiveness [2]. In fact, in order to significantly decrease the levelised cost of energy (LCOE) from PV plants without the aid of feed-in tariff and fiscal or financial incentives, maintenance and investment costs have to be reduced, while conversion efficiency needs to be further increased [3].

Thin-film solar cells based on a-Si homojunction or $\mathrm{Cu}_{2} \mathrm{ZnSnS}_{4}$ (CZTS) absorber with $\mathrm{Cd}$-free buffer layer (e.g. ZnS) do not contain either toxic or rare/critical materials $[3,4,5]$. Unfortunately, they display a low conversion efficiency. For CZTS a record efficiency of $9.1 \%$ was reached in laboratory $[5,6]$. Instead, a stabilised efficiency of $\approx 10 \%$ was obtained for single-junction cells and sub-modules [7].

In a single-junction PV device, the inherent difficulty lies in the efficient conversion of the whole solar spectrum using a single absorbing material. Use of a layered and multi-bandgap structure made of different stacked materials (multijunction cells) is a common solution. Other possibilities include intermediateband solar cell [8], up- and down-converters [9] and light-trapping strategies $[10,11]$. Such approaches require however sophisticated manufacturing and are not yet technologically mature. A much simpler and more often used way to increase electric power densities is to use optical concentration, a very efficient manner to reduce the cost of the devices by minimizing expensive active materials [12].

As an alternative to increase efficiency (so as to decrease LCOE), technology has also aimed at absorbing the sub-bandgap solar radiation, thus using it as heat to be converted into warm water [13, 14, 15], or electricity. Moreover, in principle also the heat released by PV conversion may be used in hybrid systems. Thermoelectric devices are natural candidates for such a heat-to-electricity direct conversion, and hybrid thermoelectric-photovoltaic (HTEPV) devices are nearer-term solutions due to the well established technology of thermoelectric generators (TEGs) and of single-junction PV cells [16, 17, 18, 19, 20, 21]. Promising experimental results [22] further motivate this effort.

In this work we report a computational study focused on the hybridization of two state-of-the-art devices built on single-junction a-Si and heterojunction CZTS. The evaluation of the hybridization potential for these materials is unprecedented, since most of the effort up to now has focused on silicon $[23,24,25,26,27]$, organic and DSSC [28, 19], multi-junction [29, 30, 31], and CIGS solar cells $[32,33]$. The choice of a-Si and CZTS in this work has been motivated by the mid-high value of their energy gaps that, as reported in previous publications [20, 21], make them more suitable to thermoelectric hybridization. We hybridize the materials in two different configurations. In the first instance, PV cell and TEG are optically coupled (OC) preventing the two generators to 
be in physical contact to each other (OC-HTEPV). To this purpose, a transparent back contact, and a vacuum-sealed compound parabolic concentrator $(\mathrm{CPC})$ are used. So, the sub-bandgap portion of the solar spectrum is concentrated onto the hot upper side of the TEG, so that the PV cell does not warm up while one reaches high temperatures at the TEG front. This is basically a spectrum-splitting approach. However in the reported system there is no need of an external beam splitter, as in spectrum-splitting technologies [34, 35, 36] because the solar cell itself acts as a beam splitter. In the second case, PV and TEG devices are thermally coupled putting them in direct contact. In this way the temperature of PV cells with direct thermal contact (TC) is higher but both the sub-bandgap portion of the solar spectrum and all the waste heat out of the PV cell is made available to the TEG.

For the sake of semplicity the two systems are studied by varying only the TEG device fill factor, the optical concentration, and the heat transfer coefficient at the TEG cold side. These parameters are the key factors to understand weaknesses and strengths of the coupling and cooling strategies for the two photovoltaic options. The thermoelectric material and the figure of merit were both set: the device legs have been assumed made of p-type and n-type nanostructured $\mathrm{Bi}_{2} \mathrm{Te}_{3}$ as reported by Kraemer et al. [37] and references therein. The contact and substrates resistances were neglected and the solar irradiance and ambient temperature were also kept constant, as they do not impact the comparison between TC and OC layouts. In this way we provide for the first time a complete analysis of the improvements achievable by PV-thermoelectric hybridization scanning all the physically relevant parameters ruling solar hybrid conversion. Furthermore, system scalability issues will be also discussed. It will be shown how module area rules power demand of heat dissipaters, another point often disregarded in literature.

\section{Hybrid devices description}

The schemes of the two hybrid systems considered in this work are displayed in Fig. 1. The OC-HTEPV combines a bi-facial solar cell with a CPC concentrating the sub-gap portion of the solar spectrum onto the hot side of the TEG. The CPC is a non-imaging concentrator mainly composed by two parabolic mirror segments that trap sun rays coming from any angle between the axis of CPC and the acceptance angle. The two faced segments of parabola reflect incoming light on the flat place receiver located at the base. Details of CPC operation are reported elsewhere $[38,39,40]$. In the OC-HTEPV the advantage of the temperature decoupling between the PV and TEG parts will be shown to positively impact on the HTEPV efficiency. However, OC-HTEPVs need a transparent solar cell back-contact, and a suitable solar selective absorber (SSA) to operate.

In the TC-HTEPV system, instead, the TEG is placed underneath the solar cell, in direct physical contact with it. Both the sub-gap part of the solar spectrum and the heat released by carrier thermalization are converted into heat by means of an opaque back-contact. Thus, PV bottom part and TEG top side are at the same temperature. Therefore, a convenient compromise between 


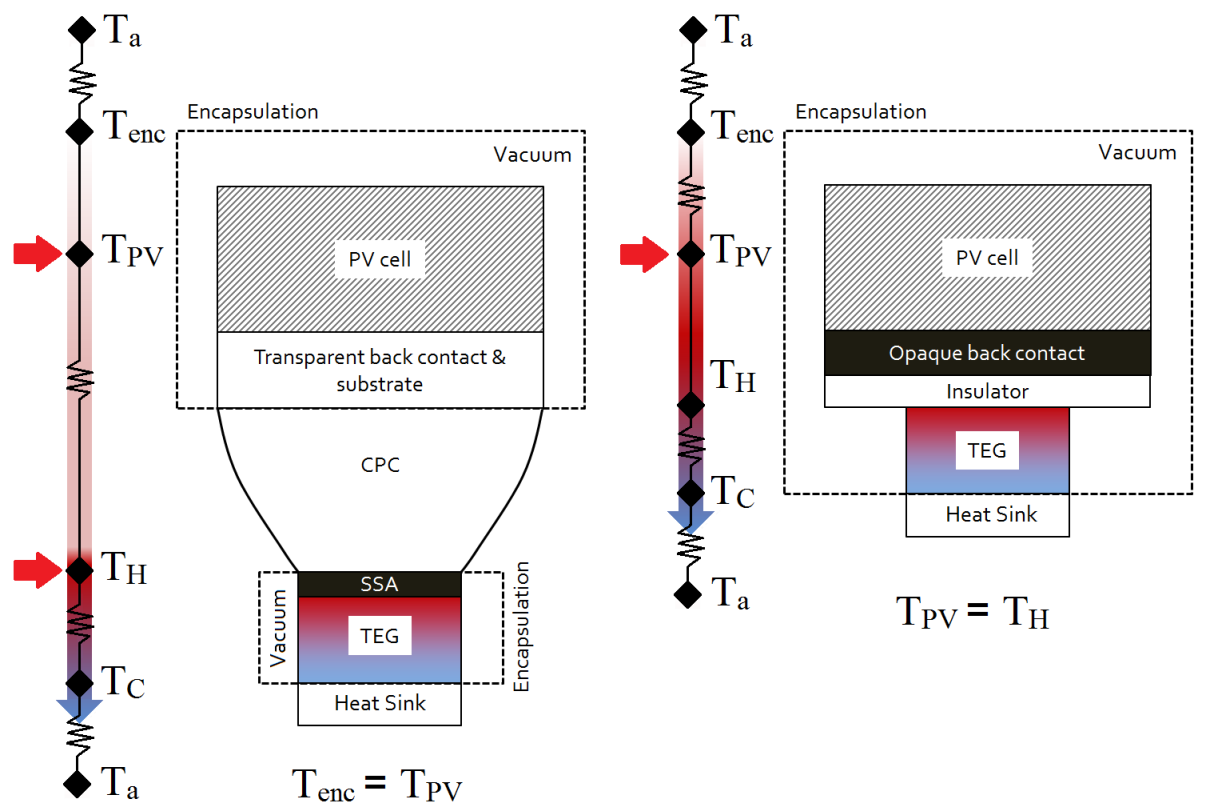

Figure 1: Scheme of the two HTEPV devices studied in this work. The expected distribution of temperatures, with the fundamental temperature nodes, and the thermal resistances among them are also displayed. The red arrows indicate the input nodes, while the vertical arrows show the expected temperature gradients.

a large temperature difference at TEG ends and the low temperature is needed to prevent PV efficiency degradation.

Figure 1 also reports the expected temperature distributions of the two system, along with the temperature nodes, and the thermal resistances among them. For the OC system the main temperature drop occurs at the TEG ends $T_{\mathrm{H}}$ and $T_{\mathrm{C}}$, and the PV stage is expected to work at relatively low temperature. Therefore, the PV temperature $\left(T_{\mathrm{pv}}\right)$ may be taken equal to that of the encapsulation $\left(T_{\text {enc }}\right)$. For the TC system, instead, $T_{\mathrm{pv}}$ is equal to $T_{\mathrm{H}}$.

In both devices the PV and the TEG stages are connected to two different electrical loads so that the HTEPV output power is simply the sum of those of the PV cell and of the TEG.

\section{Model description}

The core of the model used in this work relies on the comparison between hybrid system efficiency $\left(\eta_{\text {htepv }}\right)$, and the PV sole efficiency $\left(\eta_{\mathrm{pv}}\right)$. The HTEPV efficiency reads

$$
\begin{array}{r}
\eta_{\text {htepv }}(T)=\eta_{\mathrm{pv}}(T)+\eta_{\mathrm{teg}}(T) \eta_{\mathrm{ot}}(T)= \\
=\eta_{\mathrm{pv}}(T)+\eta_{\text {TEG }, \text { tot }}(T)
\end{array}
$$


where $\eta_{\text {ot }}$ is, following Chen [41], the system efficiency in converting the optical input power into the thermal current that flows through the TEG.

Since $\eta_{\text {htepv }}$ (as all its components) is a function of the temperature, its estimate requires the solution of the pertinent thermal circuit problem. Details about the thermal circuits along with the equations used to model them may be found in a previous publication [40]. Here we report only an outline of the system physics.

We assume that $\eta_{\mathrm{pv}}$ linearly degrades with temperature:

$$
\eta_{\mathrm{pv}}(T)=\eta_{\mathrm{pv}}^{0}\left[1-\gamma\left(T_{\mathrm{pv}}-T_{\mathrm{sc}}\right)\right]
$$

where $\eta_{\mathrm{pv}}^{0}$ is the PV efficiency at standard temperature $\left(T_{\mathrm{sc}}=25^{\circ} \mathrm{C}\right)$, and $\gamma$ is the temperature coefficient.

In this work $\eta_{\mathrm{pv}}^{0}$ is set to $7 \%$ for a single-junction a-Si module [42], and to $9.1 \%$ for CZTS cell [7]. The temperature coefficient $\gamma$ is taken instead to be $0.15 \% / \mathrm{K}$ for a-Si, and $0.17 \% / \mathrm{K}$ for CZTS $[43,44]$.

The thermoelectric efficiency depends on the thermoelectric figure of merit $(Z)$ and on the temperature at its hot and cold sides:

$$
\eta_{\text {teg }}=\frac{T_{\mathrm{H}}-T_{\mathrm{C}}}{T_{\mathrm{H}}} \frac{\sqrt{1+Z \bar{T}}-1}{\sqrt{1+Z \bar{T}}+T_{\mathrm{C}} / T_{\mathrm{H}}}
$$

Throughout this paper we set $Z=0.003 \mathrm{~K}^{-1}$, independent of the temperature, so that $Z T \approx 1$ for $T_{\mathrm{H}} \approx 100{ }^{\circ} \mathrm{C}$ and $T_{\mathrm{C}} \approx 25{ }^{\circ} \mathrm{C}[40,37,45,46,47]$.

The opto-thermal efficiency is instead the ratio between the heat flowing within the TEG $\left(Q_{\text {teg }}\right)$ and the overall incoming solar power $(S G)$ :

$$
\eta_{\mathrm{ot}}=\frac{Q_{\mathrm{teg}}}{S G}
$$

One may write $Q_{\text {teg }}$ as the difference between the heat incoming at the TEG hot surface $\left(P_{\text {teg }}^{\text {in }}\right)$ and the heat lost through thermal shunts between the device and the environment. In both $\mathrm{OC}$ and TC configurations the main sources of thermal shunts are the heat dissipation at the device front and the radiative exchange between the hot and cold sides of the TEG device.

The power absorbed by the TEG for the TC case is the sum of the heat generated by the back contact upon conversion of the sub-gap fraction of the solar spectrum $\left(L_{2 \mathrm{a}}\right)$ and the heat generated by carrier thermalization, namely

$$
P_{\mathrm{teg}}^{\mathrm{in}, \mathrm{TC}}=S G \tau_{\mathrm{enc}}\left[\left(\alpha_{\mathrm{bc}} L_{2 \mathrm{a}}\right)+\left(1-\left(L_{2 \mathrm{a}}+\eta_{\mathrm{pv}}\right)\right)\right]
$$

where $\tau_{\text {enc }}$ is the encapsulation transmittance, and $\alpha_{\mathrm{bc}}$ is the back-contact absorption coefficient. As shown by the second addend in square bracket of Eq. 4 we assume that the portion of the solar spectrum over the gap not converted by the solar cell into electrical work is fully converted in heat by carriers thermalization. We therefore neglect radiative recombination which marginally contribute to the overall balance [48]. 
In the OC case, where there are two input nodes, heat generated by carrier thermalization is radiatively transmitted to the TEG:

$$
P_{\mathrm{pv}}^{\mathrm{in}, \mathrm{OC}}=\left[1-\left(L_{2 \mathrm{a}}+\eta_{\mathrm{pv}}\right)\right] \tau_{\mathrm{enc}} S G
$$

In addition, the sub-band gap portion of the solar spectrum is converted by the SSA after being concentrated by the CPC:

$$
P_{\mathrm{SSA}}^{\mathrm{in}, \mathrm{OC}}=\alpha_{\mathrm{ssa}} \rho_{\mathrm{cpc}} L_{2 \mathrm{a}} \tau_{\mathrm{enc}} S G
$$

where $\alpha_{\mathrm{ssa}}$ is the SSA absorption coefficient, and $\rho_{\mathrm{cpc}}$ the $\mathrm{CPC}$ optical transmittance. Thus

$$
P_{\mathrm{teg}}^{\mathrm{in}, \mathrm{OC}}=f P_{\mathrm{pv}}^{\mathrm{in}, \mathrm{OC}}+P_{\mathrm{SSA}}^{\mathrm{in}, \mathrm{OC}}
$$

where $f$ is the ratio with which the heat power generated within the PV cell flows towards the TEG device instead than towards the device front surface. Such a ratio manifestly depends on the thermal resistances encountered by the heat flowing respectively toward the top $R_{\text {up }}$ and toward the bottom $R_{\text {down }}$ of the device as

$$
f=\frac{R_{\text {up }}}{R_{\text {up }}+R_{\text {down }}}
$$

To solve the thermal circuit and to calculate the system efficiencies a Wolfram Mathematica $\cap$ spreadsheet was developed using the Newton-Raphson convergence algorithm. Further details concerning the thermal resistances of the two circuits and the algorithms used to solve them are reported in a previous publication [40].

\subsection{Maximum efficiency}

In thermoelectrics the fill factor is generally defined as

$$
F F_{\text {teg }}=\frac{A_{p}+A_{n}}{A_{\text {teg }}}
$$

where $A_{\text {teg }}$ is the TEG area while $A_{p}$ and $A_{n}$ are respectively the areas of the $p$ and $n$ thermoelectric legs. In this work, instead, the HTEPV fill factor is written as

$$
F F_{\text {htepv }}=\frac{A_{p}+A_{n}}{S}
$$

(where $S$ is the PV area) as this definition better accounts for the thermoelectric material needed within the TEG device per unit area. Since $C_{\text {opt }}$ is defined as $S / A_{\text {teg }}$, one gets that $F F_{\text {teg }}=C_{\text {opt }} F F_{\text {htepv }}$. In the TC system there is no optical concentration, so that $C_{\mathrm{opt}}=1$, and $F F_{\text {htepv }}=F F_{\text {teg. }}$. In the OC case, instead, all computations reported in this subsection assume $C_{\mathrm{opt}}=4$, a choice that implies a $\mathrm{CPC}$ acceptance angle of about $15^{\circ}$, requiring only seasonal tracking adjustments for east-west orientation instead of a full tracking system.

In this subsection we aim at computing the $F F_{\text {htepv }}$ leading to the maximum efficiency. Thus we fix both the TEG geometry and the heat transfer coefficient. 


\begin{tabular}{llll}
\hline Parameter & Symbol & Value & Units \\
\hline PV efficiency at $T_{\mathrm{sc}}$ & $\eta_{\mathrm{pv}}^{0}$ & $7.0(\mathrm{a}-\mathrm{Si})$ & $\%$ \\
& & $9.1(\mathrm{CZTS})$ & $\%$ \\
PV efficiency temperature coefficient & $\gamma$ & $0.15(\mathrm{a}-\mathrm{Si})$ & $\% / \mathrm{K}$ \\
& & $0.17(\mathrm{CZTS})$ & $\% / \mathrm{K}$ \\
Sub-gap fraction of the solar spectrum & $L_{2 \mathrm{a}}$ & $0.48(\mathrm{a}-\mathrm{Si})$ & - \\
& & $0.39(\mathrm{CZTS})$ & - \\
& $\tau_{\mathrm{enc}}$ & 0.94 & - \\
& $\alpha_{\mathrm{bc}}=\alpha_{\mathrm{ssa}}$ & 0.95 & - \\
& $\rho_{\mathrm{cpc}}$ & 0.95 & - \\
Thermal exchange coefficient & $U$ & 200 & $\mathrm{~W} / \mathrm{m}^{2} \mathrm{~K}$ \\
& $G$ & 1000 & $\mathrm{~W} / \mathrm{m}^{2}$ \\
Ambient temperature & $T_{\mathrm{a}}$ & 298 & $\mathrm{~K}$ \\
TEG leg aspect ratio & $L / \sqrt{A_{n}}=L / \sqrt{A_{p}}$ & 1.22 & - \\
Thermoelectric figure of merit & $\mathrm{Z}$ & 0.003 & $\mathrm{~K}-1$ \\
Leg thermal conductivity & $\kappa$ & 1.0 & $\mathrm{~W} / \mathrm{mK}^{-1}$ \\
Seebeck coefficient & $\left|\alpha_{p, n}\right|$ & $2.25 \times 10^{-4}$ & $\mathrm{~V} / \mathrm{K}$ \\
Leg electrical conductivity & $\sigma$ & $6 \times 10^{4}$ & $\Omega^{-1} \mathrm{~m}^{-1}$ \\
\hline
\end{tabular}

Table 1: List of parameters used in this work.

More exactly, we set the TEG leg length $L$ in such a way that the geometrical ratio $L / \sqrt{A_{n}}=L / \sqrt{A_{p}}$ be constant. Table 3.1 summarizes all parameter values.

Figure 2 (left) displays $T_{\mathrm{H}}$ and the difference of temperature at the TEG sides $\Delta T$ as a function of $F F_{\text {htepv }}$, for both systems and geometries. As expected, $T_{\mathrm{H}}$ and $\Delta T$ increase when the fill factor decreases. This is simply due to the fact that a larger $F F_{\text {htepv }}$ implies wider legs, and this grants a lower TEG thermal resistance and, ultimately, a more effective heat dissipation. Furthermore, temperatures are higher for the TC case because of the direct thermal coupling between the PV and TEG parts.

Since for the TC system $T_{\mathrm{H}}=T_{\mathrm{pv}}$, it is important to remark that PV temperatures higher than $450 \mathrm{~K}$ (generally reached for fill factors lower than $0.2)$ may damage the PV device.

Minor differences are found between a-Si and CZTS cells, especially for the TC geometry. The small differences observed in the OC systems are due to their energy gaps (and thus to the different $L_{2 \mathrm{a}}$ values). Such differences are smoothed out in the TC geometries as $\alpha_{\mathrm{bc}}$ is very close to one (cf. Eq. (4)). It should also be noted that in the OC cases $T_{\mathrm{H}}$ for a-Si is slightly higher. Thus, one may expect a slightly larger TEG efficiency with a-Si cells.

Opto-thermal efficiency is instead much higher in the TC case (Fig. 2, right). This is due to two factors, namely the larger amount of heat collected by the TEG, that here may also include that arising from carrier thermalization; and the lower thermal resistance between PV and TEG sections. As a result, TEG efficiency is improved. This is clearly shown in Fig. 3, left, where the TEG efficiency $\eta_{\text {teg,tot }}$ is plotted as a function of $F F_{\text {htepv }}$. In TC geometries $\eta_{\text {teg,tot }}$ 

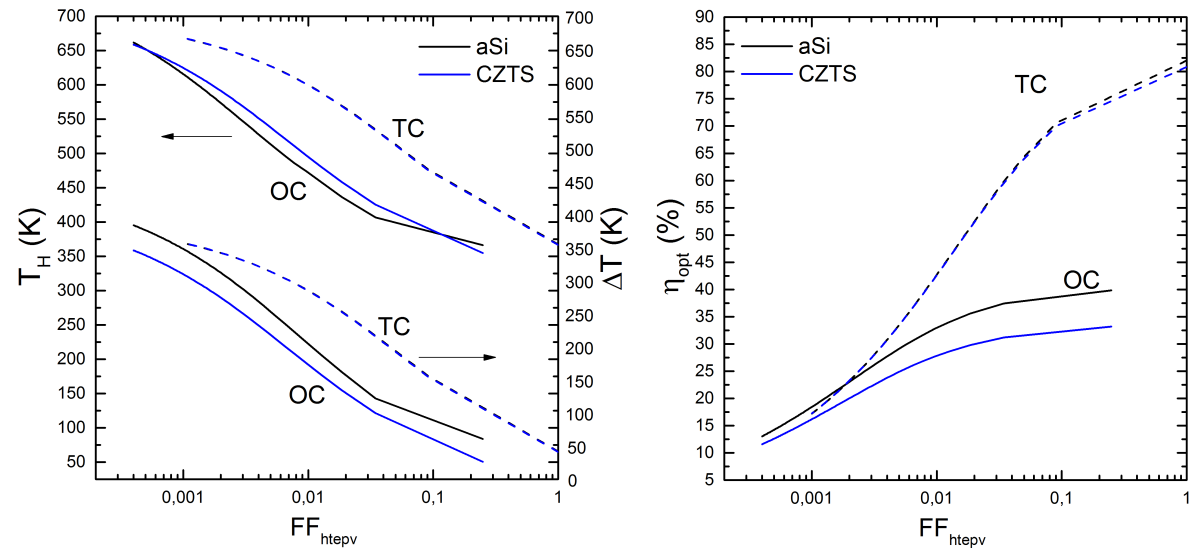

Figure 2: (left) TEG $T_{\mathrm{H}}$ and TEG $\Delta T$ vs. $F F_{\text {htepv }}$, and (right) $\eta_{\mathrm{ot}}$ vs. $F F_{\text {htepv }}$ for the two systems and the two materials considered in this work. Full and dashed lines refer to OC and TC geometries.
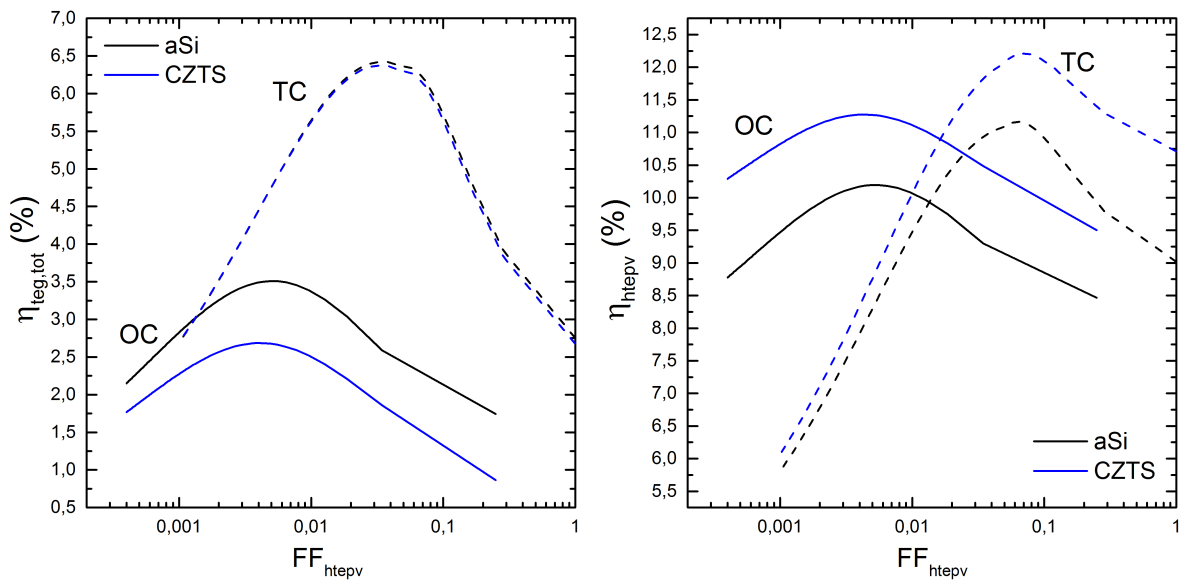

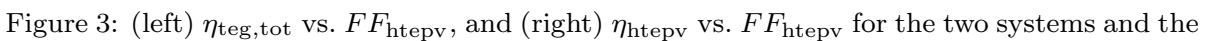
two materials considered in this work. Full and dashed lines refer to OC and TC geometries.

displays a maximum at $F F_{\text {htepv }}$ values nearly one order of magnitude larger than in the OC case. Note also that while in the former coupling scheme $\eta_{\text {teg,tot }}$ is insensitive to the PV material, in the latter it is larger when hybridizing a-Si $\mathrm{PV}$ cells. This is once again due to the differences in $L_{2 \mathrm{a}}$.

Beyond these differences, all HTEPV systems are found to perform better than the sole PV generator (Fig. 3, right). The maximum improvement is however larger for a-Si, with enhancements of $\approx 57 \%(\mathrm{TC})$ and $\approx 42 \%(\mathrm{OC})$. With CZTS one finds instead an improvement of $\approx 35 \%$ (TC) and $\approx 24 \%$ (OC). Once again, that the maximum $\eta_{\text {htepv }}$ be larger in the TC case is a direct consequence of the higher opto-thermal efficiency. Note also how the maximum 

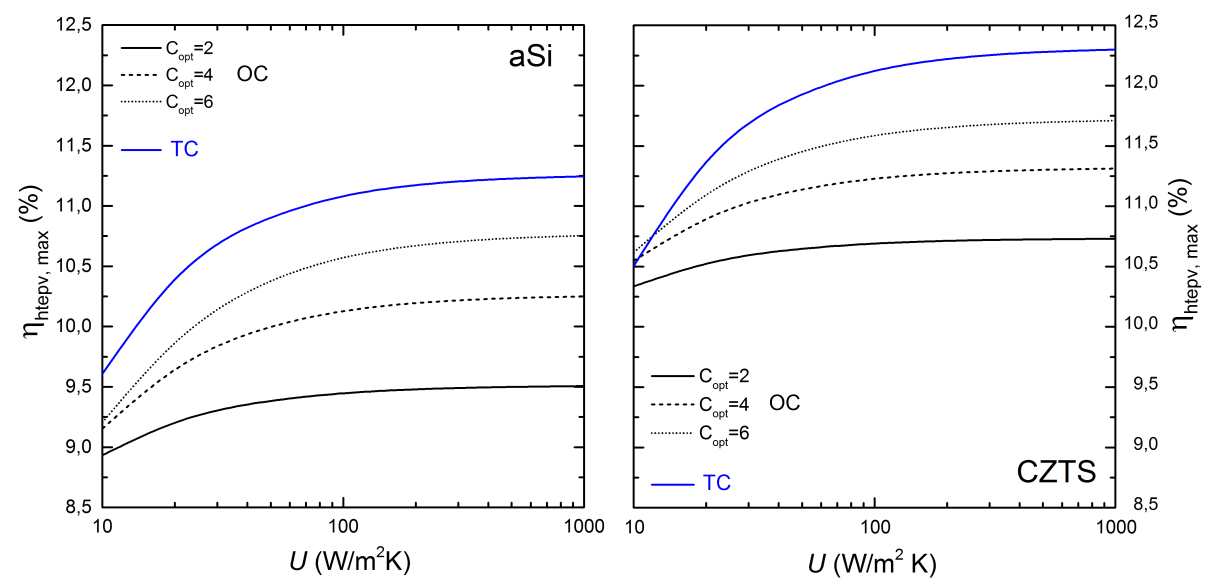

Figure 4: Maximum HTEPV efficiency as a function of the dissipater thermal coefficient $U$. Note that in all cases the efficiency reaches a plateau around $200 \mathrm{~W} / \mathrm{m}^{2} \mathrm{~K}$.

is much narrower for TC schemes due to the rapid decrease of the PV efficiency with temperature. For both materials efficiencies reach maxima for smaller HTEPV fill factors in OC systems, meaning that such a geometry requires less thermoelectric material per unit area.

\section{Result and Discussion}

\subsection{Role of concentration and dissipater thermal coefficient}

We further proceeded to optimize the power output upon the concentration and the dissipater thermal coefficient $U$.

The maximum HTEPV efficiency $\left(\eta_{\text {hetpv,max }}\right)$ as a function of $U$ is displayed in Fig. 4. Three possible values of $C_{\mathrm{opt}}$ are considered for OC. In all cases we took a PV area $S$ of $0.018 \mathrm{~m}^{2}$ to keep CPC size acceptable. One finds that, although the efficiency of the TC systems is larger (Fig. 3), its power output is smaller since the optical concentration enhances the input power in the OC system. Note also that maximum efficiency reaches a plateau for values of $U$ larger than $200 \mathrm{~W} / \mathrm{m}^{2} \mathrm{~K}$, with improvements less than $\approx 2.5 \%$ for $U$ values in excess of $70-80 \mathrm{~W} / \mathrm{m}^{2} \mathrm{~K}$. Thus, moderate heat exchanges are needed to enable suitable temperature differences across the TEG section. Nonetheless, they are not achievable using passive dissipater. Therefore, the power consumption of the heat dissipater, that has clearly to be subtracted from the HTEPV power output, needs to be quantified. To this purpose we used the dissipater design, with parallel circular channels proposed by Yazawa and Shakouri [49]. Diameter, number of channels, and heat exchanger thickness were sized following impedance matching condition, so that convection from the fin surface match that of the flowing fluid [50]. We further assumed a fluid laminar flow, since in all cases Reynolds number were verified to be low [51]. 

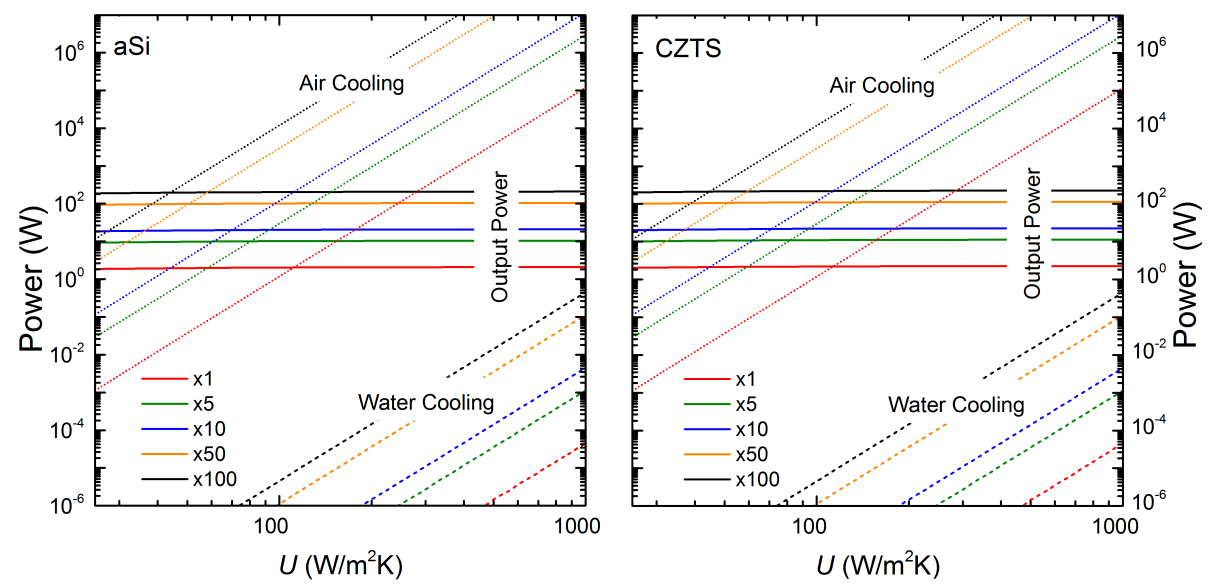

Figure 5: Electrical power output and power consumption by water-based and air-based active heat exchangers versus $U$ at maximum efficiency for TC geometries. Data are reported for sub-module assemblies from 1 to 100 sub-modules.

Limiting to the TC case, one obtains (Fig. 5) that air convection is convenient only for very low $U$ values, as for larger values the power needed to force the air flow becomes comparable to that produced by the cell itself. Water-based dissipaters are far more effective and less demanding as of power consumption, enabling effective heat extraction with a negligible reduction of the net cell power output.

Realistic computations for the OC geometry would require a deeper analysis of the reciprocal orientation of the HTEPV sub-modules. However the ratio between the electric power output and the dissipater power consumption may only be better than in TC geometries since the area to be cooled down is smaller. Thus, the general conclusion may be drawn that water-based dissipation is a viable, power-effective solution to enhance the effiiency of HTEPV devices.

\subsection{Role of the ambient conditions}

Ambient conditions may play a relevant role on the final system efficiency. The effect of the ambient temperature $T_{\mathrm{a}}$, and of the solar irradiation $G$ as a function of $U$ was considered(Fig. 6). As expected, an increase of $T_{\text {a }}$ leads to a decrease of the system efficiency and vice versa, manly because of a reduction of the heat gradient between the hot and cold thermoelectric sides. Concerning instead solar irradiation, smaller efficiencies are found for smaller values of $G$ because of the smaller incoming power, which leads in turn to a smaller temperature difference across the TEG sides.

In general, the effect of the solar irradiation is more important than that of the ambient temperature, and it affects more the TC systems than the OC ones. This can be explained considering that the ambient conditions mainly impact on the thermoelectric part of the system. Since in the TC case the thermoelectric 

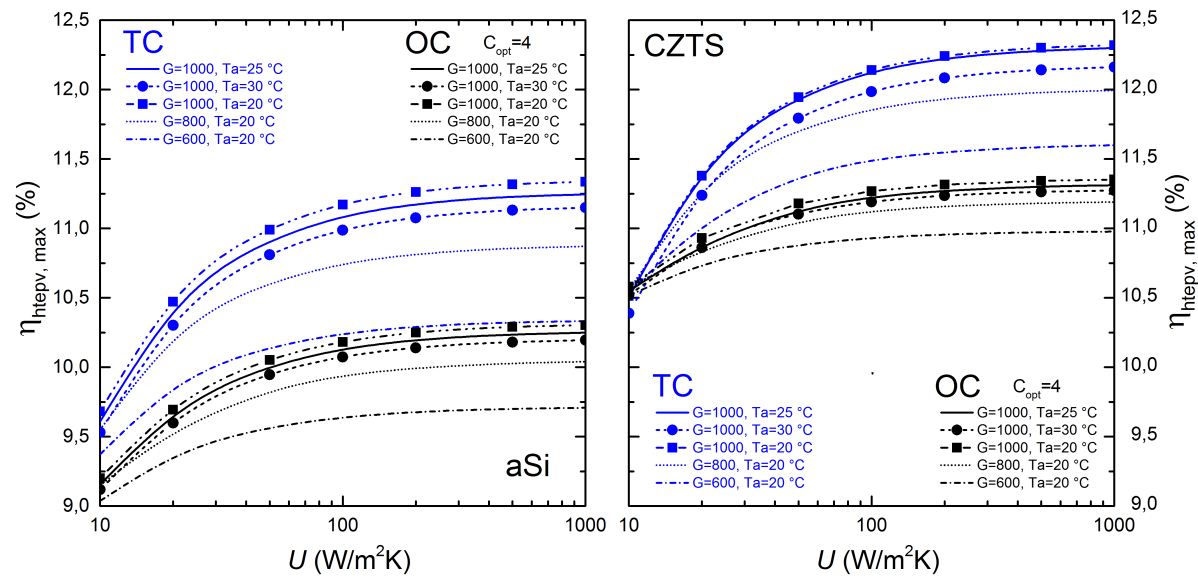

Figure 6: Maximum HTEPV efficiency as a function of the dissipater thermal coefficient $U$ under different ambient conditions. For the sake of clarity, for the OC layout only the case $C_{\text {opt }}=4$ is reported.

contribution is larger than in the OC system, TC systems are more sensitive to ambient condition variations.

The effect of the wind velocity on the system efficiency was computed instead using the well-known empirical equation [52]

$$
h=2.8+3.0 v
$$

which sets the convective heat loss coefficient $h$ at the encapsulation top surface as a function of the wind velocity $v$. The influence of this parameter was found to be very marginal (on average an absolute value of $\approx 0.1 \%$ passing from 2 to $5 \mathrm{~m} / \mathrm{s}$ ). This is mostly due to the fact that in all the systems the thermal exchange from the cell top is minimal. Therefore, since wind velocity changes only the heat dissipation at system top surface its effect on the efficiency is negligible.

\subsection{Technological limitations}

Although TC-HTEPV converters are found to outperform their OC counterpart (Fig. 3), the temperature equalization between PV cell and TEG hot side sets additional constraints. As mentioned, if $T_{\mathrm{H}}$ is too high some of the PV components, such as the contact grid, or even some of the layers of the PV part, may suffer short- or long-term degradation. This point is made even clearer by plotting the value of $T_{\mathrm{H}}$ at maximum HTEPV efficiency for the TC case (Fig. 7). One finds that $T_{\mathrm{H}}$ ranges between 500 and $520 \mathrm{~K}$ for a-Si, and between 480 and $500 \mathrm{~K}$ for CZTS (blue lines in Fig. 7). All temperatures are critically high for most PV components. Thus, a fairer comparison between TC and OC geometries may be obtained by plotting $T_{\mathrm{H}}$ values of the TC system at which the $\mathrm{TC}$ efficiency equals the maximum efficiency for the OC system, as a function 

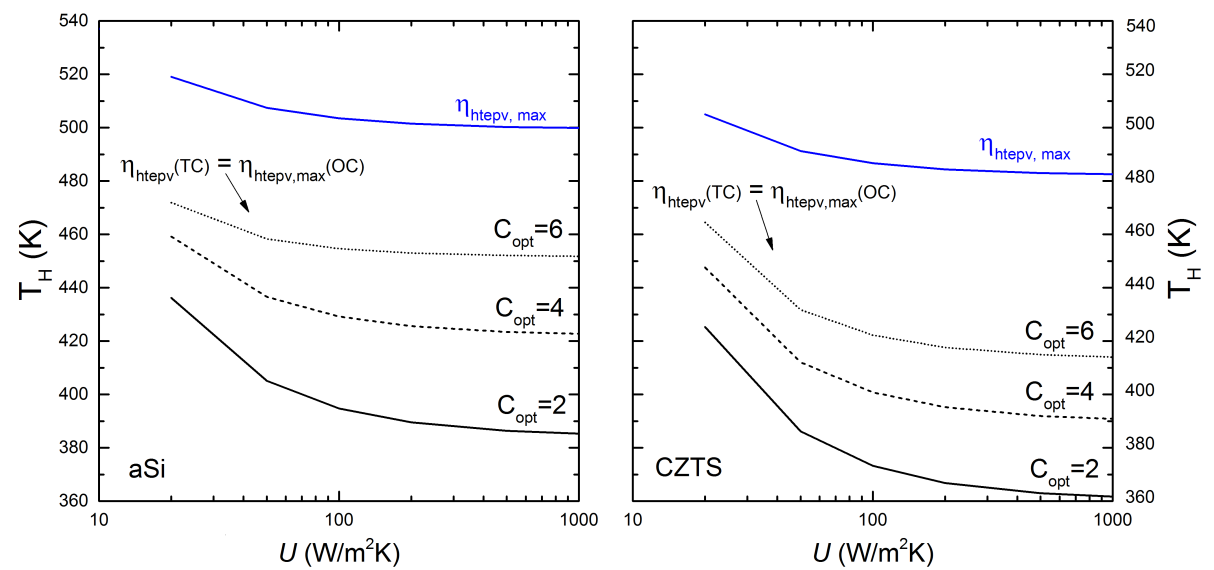

Figure 7: Dependency on the heat dissipater thermal coefficient for a-Si and CZTS-based HTEPV cells of the TEG hot-side temperature (a) at maximum HTEPV efficiency for TC cells (blue line) and (b) at which $\eta_{\text {hetpv }}$ in TC systems equals $\eta_{\text {hetpv,max }}$ in OC systems (black lines).

of heat exchange coefficient (black lined in Fig. 7). Taking for instance $C_{\mathrm{opt}}=$ 4 , for $U>100 \mathrm{~W} / \mathrm{m}^{2} \mathrm{~K}$ one finds that $T_{\mathrm{H}}$ spans between 430 and $440 \mathrm{~K}$ for a-Si, and from 390 to $400 \mathrm{~K}$ for CZTS. Both temperature ranges are actually more reasonable for $\mathrm{PV}$ devices. Therefore, $\mathrm{OC}$ geometries are to be preferred over TC-HTEPV as of their capability to achieve a given efficiency while keeping the PV temperature lower. In addition, since OC systems have smaller exchange areas at the TEG side, they enable important LCOE reduction due to the high incidence of heatsink costs on the HTEPV installation cost [53]. Nonetheless, LCOE is unavoidably increased by the CPC and the additional SSA elements. Also, the overall system is far bulkier than TC-HTEPV cells, a factor that might partially limit its usability.

It should be noted that in both OC and TC HTEPV converters the actual feasibility of hybrid solar cells depends however upon key material issues. Effective sub-bandgap absorbers with a large thermal conductivity are actually needed for TC-HTEPVs, while transparent back contacts are required for OC-HTEPVs. Thus, in both cases the deployment of HTEPV devices depends on the availability of materials that meet challenging yet not impossible technological requirements. Effective, almost ideal absorbers are already available $[28,54]$, although their thermal conductivity may be improved. Transparent contacts may require instead a more significant research effort to reach the values of electric resistivity that would enable the actual design of OC-HTEPV cells. Transparent conductive oxides still lack of the very low resistivity needed for large current densities to be collected at the PV backside. Very recently, evidence of the usability of highly conductive iodine-doped $\mathrm{CuI}$ was put forward [55]. It is then probably not too optimistic to believe that effort and creativity might shortly have the way for OC-HTEPV cells to actually compete in PV 
hybridization.

\section{Conclusions}

We have shown that both HTEPV systems, either in their OC or TC configuration, always result in an increased efficiency with respect to the PV case. Specifically, the higher is the bandgap of the absorbing material, the higher are the computed maximum efficiencies, both in single-junction a-Si and in heterojunction CZTS cell. Enhancements are respectively $\approx 57 \%$ and $\approx 35 \%$ in TC configuration, and $\approx 42 \%$ and $\approx 24 \%$ in OC configurations. Contact-coupled configurations resulted in higher efficiencies due to the more efficient conversion of waste heat incoming from the PV devices to the TEGs. However, failure or anyway a reduced lifetime might occur due to the too high temperatures that must be attained to achieve optimal efficiency. Thus, a trade-off has to be reached between efficiency and reliability, accepting suboptimal conversion rates. Instead, in the OC configurations the PV temperature is more conveniently managed.

This also leads to a remarkable reduction of the heat sink areas - with an expected reduction of fabrication costs compared to TC-HTEPV. In addition, the needed volume of thermoelectric materials per unit area also favours OC over TC systems in both types of PV cells, as a consequence of the smaller HTEPV fill factors at maximal efficiency. However, the larger size of the the system along with the additional cost of the CPC unit might balance pros and cons of TC and OC geometries.

In both OC and TC HTEPV converters the actually feasibility of hybrid solar cells depends however upon key material issues. Effective sub-bandgap absorbers with a large thermal conductivity are actually needed for TC-HTEPVs, while transparent back contacts are required for OC-HTEPVs. Thus, in both cases the deployment of HTEPV devices depends on the availability of materials that meet challenging yet not impossible technological requirements. 
[1] M. Hook, X. Tang, Depletion of fossil fuels and anthropogenic climate change-A review , Energy Policy 52 (2013) 797-809.

[2] O. E. Et al., Climate Change 2014: Mitigation of Climate Change. Contribution of Working Group III to the Fifth Assessment Report of the Intergovernmental Panel on Climate Change, Cambridge University Press: Cambridge, UK, New York, NY, USA, 2014.

[3] P. V. Et al., Future renewable energy costs: solar photovoltaics (2015), KIC-InnoEnergy Renewable Energies Report-website: www.kicinnoenergy.com.

[4] H. Katagiri, $\mathrm{Cu}_{2} \mathrm{ZnSnS}_{4}$ thin film solar cells, Thin Solid Films 480-481 (2005) 426-432.

[5] X. Liu, Y. Feng, H. Cui, F. Liu, X. Hao, G. Conibeer, D. B. Mitzi, M. Green, The current status and future prospects of kesterite solar cells: a brief review , Progress in photovoltaics: research and applications 24 (2016) 879-898.

[6] T. Fukano, S. Tajima, T. Itoh, W. Wang, M. T. Winkler, O. Gunawan, T. Gokmen, T. K. Todorov, Y. Zhu, D. B. Mitzi, Enhancement of Conversion Efficiency of $\mathrm{Cu}_{2} \mathrm{ZnSnS}_{4}$ Thin Film Solar Cells by Improvement of Sulfurization Conditions, Applied physics express 6 (6) (2013) 062301.

[7] M. A. Green, K. Emery, Y. Hishikawa, W. Warta, E. D. Dunlop, Solar cell efficiency tables (version 46), Progress in Photovoltaics: Research and Applications 23 (2015) 805-812.

[8] A. Luque, A. Martì, C. Stanley, Understanding intermediate-band solar cells, Nature photonics 6 (2012) 146-152.

[9] D. Verma, T. O. Saetre, O.-M. Midtgård, Review on up/down conversion materials for solar cell application, Photovoltaic Specialists Conference (PVSC), 2012 38th IEEE (2012) 2608-2613.

[10] I. Kuznetsov, M. Greenfield, Y. Mehta, W. Merchan-Merchan, G. Salkar, A. Saveliev, Increasing the solar cell power output by coating with transition metal-oxide nanorods, Applied Energy 88 (11) (2011) 4218-4221, cited By 13.

[11] H. A. Atwater, A. Polman, Plasmonics for improved photovoltaic devices, Nature materials 9 (3) (2010) 205-213.

[12] R. M. Swanson, The Promise of Concentrators, Progress in photovoltaics: research and applications 8 (2000) 93-111.

[13] M. Li, X. Ji, G. Li, S. Wei, Y. Li, F. Shi, Performance study of solar cell arrays based on a Trough Concentrating Photovoltaic/Thermal system, Applied Energy 88 (9) (2011) 3218-3227. 
[14] T. Chow, A review on photovoltaic/thermal hybrid solar technology, Applied Energy 87 (2) (2010) 365-379.

[15] F. Sarhaddi, S. Farahat, H. Ajam, A. Behzadmehr, M. Mahdavi Adeli, An improved thermal and electrical model for a solar photovoltaic thermal (PV/T) air collector, Applied Energy 87 (7) (2010) 2328-2339.

[16] M. Telkes, Solar Thermoelectric Generators, Journal of Applied Physics 25 (6) (1954) 765-777.

[17] Y. Vorobiev, J. González-Hernández, P. Vorobiev, L. Bulat, Thermalphotovoltaic solar hybrid system for efficient solar energy conversion, Sol. Energy 80 (2006) 170-176.

[18] K.-T. Park, S.-M. Shin, A. S. Tazebay, H.-D. Um, J.-Y. Jung, S.-W. Jee, M.-W. Oh, S.-D. Park, B. Yoo, C. Yu, J.-H. Lee, Lossless hybridization between photovoltaic and thermoelectric devices., Scientific reports 3 (2013) $422-427$.

[19] Y. Zhang, J. Fang, C. He, H. Yan, Z. Wei, Y. Li, Integrated energyharvesting system by combining the advantages of polymer solar cells and thermoelectric devices, Journal of Physical Chemistry C 117 (47) (2013) 24685-24691.

[20] B. Lorenzi, M. Acciarri, D. Narducci, Conditions for beneficial coupling of thermoelectric and photovoltaic devices, Journal of Materials Research 30 (17) (2015) 2663-2669.

[21] D. Narducci, B. Lorenzi, Challenges and Perspectives in Tandem Thermoelectric-Photovoltaic Solar Energy Conversion, IEEE Transactions on Nanotechnology 15 (3) (2016) 348-355.

[22] W. Zhu, Y. Deng, Y. Wang, S. Shen, R. Gulfam, High-performance photovoltaic-thermoelectric hybrid power generation system with optimized thermal management, Energy 100 (2016) 91-101.

[23] W. Sark, Feasibility of photovoltaic - thermoelectric hybrid modules, Applied Energy 88 (8) (2011) 2785-2790, cited By 68.

[24] M. Fisac, F. X. Villasevil, A. M. López, High-efficiency photovoltaic technology including thermoelectric generation, Journal of Power Sources 252 (2014) 264-269.

[25] R. Lamba, S. C. Kaushik, Modeling and performance analysis of a concentrated photovoltaic-thermoelectric hybrid power generation system, Energy Conversion and Management 115 (2016) 288-298.

[26] A. Makki, S. Omer, Y. Su, H. Sabir, Numerical investigation of heat pipebased photovoltaic-thermoelectric generator (HP-PV/TEG) hybrid system, Energy Conversion and Management 112 (2016) 274-287. 
[27] Y. Luo, L. Zhang, Z. Liu, Y. Wang, F. Meng, J. Wu, Thermal performance evaluation of an active building integrated photovoltaic thermoelectric wall system, Applied Energy 177 (2016) 25-39, cited By 3.

[28] N. Wang, L. Han, H. He, N.-H. Park, K. Koumoto, A novel highperformance photovoltaic thermoelectric hybrid device, Energy Environ. Sci. 4 (2011) 3676.

[29] A. Rezania, L. Rosendahl, Feasibility and parametric evaluation of hybrid concentrated photovoltaic-thermoelectric system, Applied Energy 187 (2017) 380-389.

[30] J. Zhang, Y. Xuan, Investigation on the effect of thermal resistances on a highly concentrated photovoltaic-thermoelectric hybrid system, Energy Conversion and Management 129 (2016) 1-10.

[31] O. Beeri, O. Rotem, E. Hazan, E. A. Katz, A. Braun, Y. Gelbstein, Hybrid photovoltaic-thermoelectric system for concentrated solar energy conversion: Experimental realization and modeling, Journal of Applied Physics 118 (11).

[32] J. Zhang, Y. Xuan, L. Yang, Performance estimation of photovoltaicthermoelectric hybrid systems, Energy 78 (2014) 895-903.

[33] T.-J. Hsueh, J.-M. Shieh, Y.-M. Yeh, Hybrid Cd-free CIGS solar cell/TEG device with $\mathrm{ZnO}$ nanowires, Progress in Photovoltaics: Research and Applications 23 (4) (2015) 507-512.

[34] X. Ju, Z. Wang, G. Flamant, P. Li, W. Zhao, Numerical analysis and optimization of a spectrum splitting concentration photovoltaicthermoelectric hybrid system, Solar Energy 86 (6) (2012) 1941-1954.

[35] C. Shou, Z. Luo, T. Wang, W. Shen, G. Rosengarten, W. Wei, C. Wang, M. Ni, K. Cen, Investigation of a broadband $\mathrm{tio}_{2} / \mathrm{sio}_{2}$ optical thin-film filter for hybrid solar power systems, Applied Energy 92 (2012) 298-306, cited By 24.

[36] P. Huen, W. A. Daoud, Advances in hybrid solar photovoltaic and thermoelectric generators, Renewable and Sustainable Energy Reviews (2016) In press.

[37] D. Kraemer, B. Poudel, H.-P. Feng, J. C. Caylor, B. Yu, X. Yan, Y. Ma, X. Wang, D. Wang, A. Muto, K. McEnaney, M. Chiesa, Z. Ren, G. Chen, High-performance flat-panel solar thermoelectric generators with high thermal concentration, Nature materials 10 (7) (2011) 422-427.

[38] A. Rabl, Optical and thermal properties of compound parabolic concentrators, Solar Energy 18 (1976) 497. 
[39] R. Winston, H. Hinterberger, Principles of Cylindrical Concentrators for Solar Energy, Solar Energy 16 (1974) 89.

[40] B. Lorenzi, G. Contento, V. Sabatelli, A. Rizzo, D. Narducci, Theoretical Analysis of Two Novel Hybrid Thermoelectric - Photovoltaic Systems Based on CZTS Solar Cells, J. Nanosci. Nanotechnol. 17 (2017) 1608-1615.

[41] G. Chen, Theoretical efficiency of solar thermoelectric energy generators, Journal of Applied Physics 109 (10).

[42] J. Schimdtke, Commercial status of thin-film photovoltaic devices and materials, Optics Express A 18 (2010) 477-486.

[43] A. Virtuani, D. Pavanello, G. Friesen, Overview of Temperature Coefficients of Different Thin Film Photovoltaic Technologies, in: Proc. 25th EU PVSEC, 2010, pp. $4248-4252$.

[44] P. Lin, L. Lin, J. Yu, S. Cheng, P. Lu, Q. Zheng, Numerical simulation of $\mathrm{Cu}_{2} \mathrm{ZnSnS}_{4}$ based solar cells with $\mathrm{In}_{2} \mathrm{~S}_{3}$ buffer layers by SCAPS-1D, Journal of Applied Science and Engineering 17 (4) (2014) 383-390.

[45] T. M. Tritt, M. a. Subramanian, Thermoelectric Materials, Phenomena, and Applications: A Bird's Eye View, MRS Bulletin 31 (March) (2006) 188-198.

[46] G. J. Snyder, E. S. Toberer, Complex thermoelectric materials, Nature materials 7 (2) (2008) 105-114.

[47] J. R. Sootsman, D. Y. Chung, M. G. Kanatzidis, New and old concepts in thermoelectric materials, Angewandte Chemie - International Edition 48 (46) (2009) 8616-8639.

[48] O. Dupré, R. Vaillon, M. A. Green, A full thermal model for photovoltaic devices, Solar Energy 140 (2016) 73-82.

[49] K. Yazawa, A. Shakouri, System optimization of hot water concentrated solar, in: Thermal Issues in Emerging Technologies, ThETA 3, Cairo Egypt, Dec 19-22nd 2010, 2010, pp. 283-290.

[50] K. Yazawa, G. L. Solbrekken, A. Bar-Cohen, Thermofluid Design of Energy Efficient and Compact Heat Sinks, in: 2003 International Electronic Packaging Technical Conference and Exhibition, Volume 2, ASME, 2003, pp. 509-516.

[51] Y. A. Cengel, Heat Transfer - A practical approach, 2nd Edition, McGrawHill, 2003, pp. 423-436.

[52] J. Duffie, W. Beckman, Solar Engineering of Thermal Processes, 4th Edition, John Wiley \& Sons, Ltd., 2003, pp. 163-165. 
[53] K. Yazawa, A. Shakouri, Cost-Efficiency Trade-off and the Design of Thermoelectric Power Generators, Environmental Science \& Technology 45 (17) (2011) 7548-7553.

[54] H. Rongtao, M. Bin, M. Liping, C. Yongzhi, M. Le, High temperature selective absorption coating based on stainless steel material and manufacture method thereof, China Patent n. 102534497.

[55] C. Yang, M. Kneiß, M. Lorenz, M. Grundmann, Room-temperature synthesized copper iodide thin film as degenerate p-type transparent conductor with a boosted figure of merit, Proceedings of the National Academy of Sciences 113 (46) (2016) 12929-12933. 